\title{
Defining The Identity of Technocentric Transformations In An Urban Edge - A Case of Kazhakuttom, Trivandrum
}

\author{
SHAHANAZ JALEEL ${ }^{1 *}$ AND JACOB CHERIAN ${ }^{2}$ \\ ${ }^{1}$ Assistant Professor, Department of Architecture, TKM College of Engineering, \\ Kollam, Kerala \\ ${ }^{2}$ Architect at Place Design, Ernakulam, Kerala \\ *Email: shahanaz.jaleel@gmail.com
}

Received: December 18, 2015I Revised: December 22, 2015| Accepted: January 08, 2016

Published online: July 04, 2016

The Author(s) 2016. This article is published with open access at www.chitkara.edu.in/publications

\begin{abstract}
Technocentric developments often result in creating a socio-spatial duality in different contexts, forming a place identity with contesting nature of the global and local settlements. The location of technocentric campuses in the urban periphery results in a haphazard development with little response to the context, also resulting in social strife and generating possibilities of marginalisation and gentrification of the local communities in near future. This will affect the urban life due to a discontinuity in the urban realm. The current transformations include functional change of existing residential units into mixed-use commercial and lodging facilities and, conversion of vacant plots into high density residential and commercial functions.

The transformations seen at the site of the case study also include the conversion of the earlier dead bypass stretch into a highly active corridor with restaurants, informal eateries, and hang out areas targeting the techie population which adds to the changing urban identity of Kazhakuttom. This paper attempts to envision the future development and urban identity of Kazhakuttom as the new economic district of Trivandrum city as a favourable work-live-entertainment environment with support facilities, while also incorporating local aspirations to ensure social and spatial continuity.

The methodology involved a detailed macro and micro level primary study and analysis of Kazhakuttom so as to identify the issues. The methodology included correlating the primary study with literature study on concepts and theories of identity, glocalization, and hybridization. The design cues from related technocentric contexts in Silicon Valley, Gurgaon and Bengaluru allowed developmemnt of design strategies for integrating the technocentric campuses with the local context and culture of the place.
\end{abstract}

Keywords: Technocentric Development; Technocentric Transformations; Urban Edge; Urban Identity
Creative Space (CS)

Vol-4, No-1

July 2016

pp. 97-102

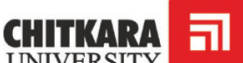

(C)2014 by Chitkara

University. All Rights

Reserved. 
Jaleel, $\mathrm{S}$

Cherian, J

\section{INTRODUCTION}

Kazhakuttom is an emerging technocentric zone on the urban edge of Trivandrum city, characterized by IT/ITES developments forming a Special Economic Zone (SEZ). It is located between Attingal and Trivandrum city, at the junction of the NH-47 and NH bypass. It is well connected with the airport and Kazhakuttom Railway Station (Fig. 1) According to the 2011 Census Kazhakuttom has a population of 38,837 [3]. The major technocentric campuses in the region are - Technopark, proposed Technopark Phase-III, UST Global and, the Infosys Campus. These are integral to the economic growth of the city. Technopark alone has 47,000 employees [18], with more than $50 \%$ a floating population from all over India (Fig. 2a). In addition, Kazhakuttom has numerous educational institutions. At a macro scale, the presence of numerous institutions has made the place very fragmented. The catalytic effect of technocentric developments, e.g.,banks, hotels, restaurants, hostels, lodges, hyper markets, etc. that cater to the new population - has given rise to scattered developments along the bypass and adjoining areas (Fig. 2b).

These new global developments, characterised by introverted and exclusive iconic buildings form zones, which strongly contrast with the local context. This creates inactive edges along campuses in Kazhakuttom, which affects the continuity of the urban realm. They stand as independent entities, poorly integrated with the context and have affected the identity of the place. The completion of Technopark Phase III in the near future will generate an additional 50,000 jobs [18], which will catalyze even more service-based developments. They have to be well integrated such that the inactive edges lacking visual continuity and activity causing fragmentation is minimized.

\section{ISSUES}

Various issues identified during the primary study include the following:

- The presence of numerous educational and technocentric campuses have created a dehumanised and inactive realm in the edges of the city.

- Haphazard growth of technocentric-based catalytic services and informal developments.

- Spatial duality of the global and local developments.

- Lack of public realm in Kazhakuttom, which is facing development pressure due to technocentric expansion.

- Lack of entertainment and recreational facilities for the new population. 


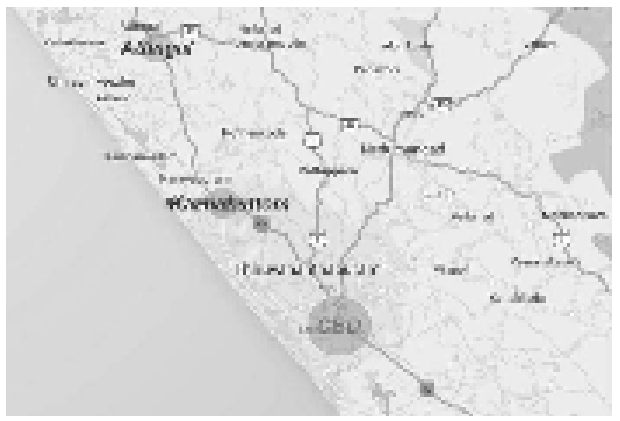

Figure 1: Image showing the location of Kazhakuttom w.r.t to Trivandrum, (Image source: Data adapted from google maps).

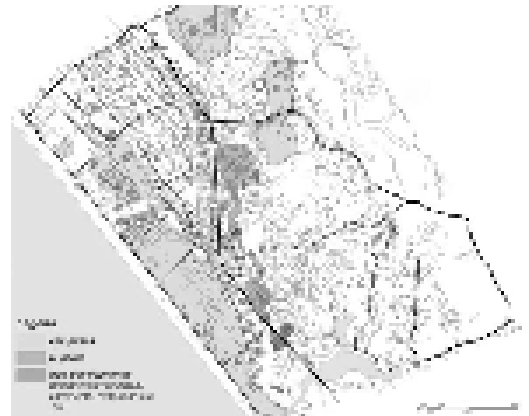

Figure 2a: The contexts of technocentric developments (IT parks) and the various campuses
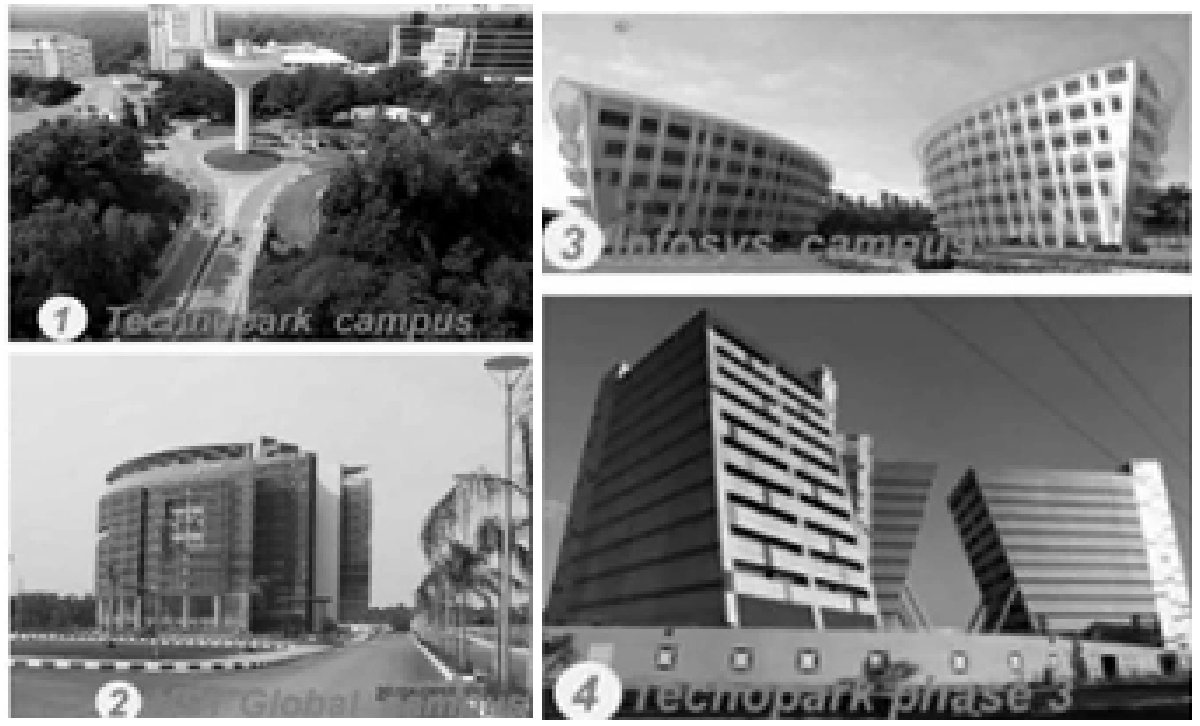

Figure 2b: The various campuses - Technopark, UST Global, Infosys and Technopark PhaseIII (Image source: Authors).

\section{CONCERN}

The current development trend in Kazhakuttom is likely to result in a sociospatial and economic disparity in which the duality of the local and the global $\mathrm{d}$, local and influx population can result in crime and violence, adversely affecting the urban life. Therefore, it is essential that such developments are well integrated within the local context and setting. This paper aims to arrive at strategies to enhance the identity of technocentric transformations by adopting Glocalization and Hybridization as key concepts. 
Jaleel, S

Cherian, J

\section{TECHNOCENTRIC DEVELOPMENTS}

Technocentric developments are technology based transnational firms that are nodes in the global economic grid. They emerged after economic liberalization in 1990s and, are characterized by clusters of global firms with shared infrastructure. The clusters catalyse a new range of service-based developments such as banking, hostels, hotels, real estate and construction, marketing, entertainment hubs, etc. to cater to the new economic need and the new affluent influx population. Due to their catalytic effects, technocentric developments are usually based on rail and airport connectivity and located in the urban edge. The absence of planning norms in such areas causes catalytic growth in an unplanned, haphazard manner. Technocentric firms develop as exclusive campuses with high security facilities, and are characterised by extroverted buildings with global iconic forms.

\subsection{Spatial Characteristics}

Technocentric growths are the new Silicon Geography of duplication [15]. They are introverted and exclusive and have transplanted iconic forms with little references to local conditions. According to Sasika Sassen (1996), this creates new dynamics of the marginalized local, together with an occupational change in the service sector and, adoption of a global lifestyle by the affluent. Thus, a new landscape of urban glamour, in duality with the local war zone, is developed and, such cities face aocio-spatial and economic polarisation [14]. Such a phenomenon has already been reported in the case of Bengaluru (Fig. 3, Fig. 4, Fig. 5).

\subsection{Spatial Integration}

Spatial integration is integral to ensure a sense of continuity in the public realm. This could be achieved through mixed-use developments, linkages, edge treatments, introduction of activities in the public realm.

\subsection{Glocalization}

Glocalization occurs wherever the local and the global coexist and, expresses the way global dynamics are reinterpreted locally. The local and global scales are interpreted to achieve context dependent outcomes $[13,16]$.

\subsection{Hybrid Forms}

The shift in time-space relations, due to time-space compression [8], has caused a discontinuity in the representation of identity, which is now characterised by 

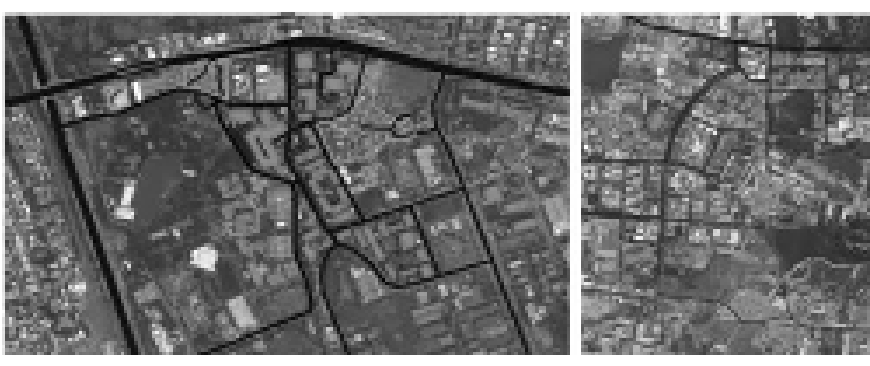

Figure 3:

Technocentric context and its neighborhoods in electronic city and Whitefield in Bengaluru (Image source: Authors adapted data from Google Maps).

Figure 4: Sketches
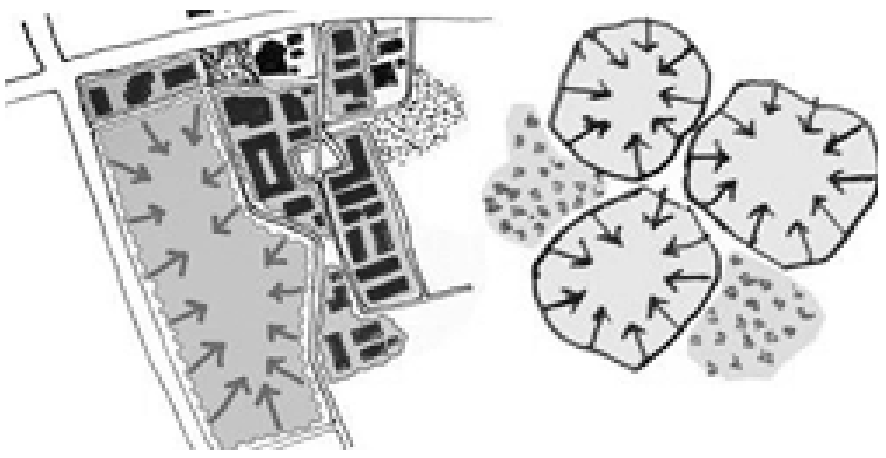

showing the fragmentation and spatial segregation of tech clusters in Bengaluru (Image source: Authors).
Defining The

Identity of

Technocentric

Transformations

In An Urban

Edge - A Case of Kazhakuttom,

Trivandrum

homogenisation and a trend towards iconic western models. A synthesis of the traditional, the local or the regional aspects, in a reinterpreted manner, is called a Hybrid [9]. The adaptation of place-based identity reference ensures a sense of continuity and belonging between the local and the global fascinations. Hybrid urban development could be achieved through (i) Reinterpretation of local patterns, geometries, façade, etc., (ii) Spatial organisations in new proportions and scales, (iii) Site specificity and, (iv) Climatic adaptation [9]. The identity relation in the global age basically searches for a solution for the loss of continuity and belongingness to a place, with place references familiar to our minds. Identity representations are mostly grounded on regionalist aspects that are to be addressed in design while engaging with global requirements [9].

\section{IDENTITY}

It is the state of having unique identifying characteristics that reflect people's traditions, culture and aspirations and are created through complex interaction of natural, social and built components [6]. The components of identity are people and activity, place and its physical setting and, perceptions and fascinations [1]. Place identity is defined by the physical attributes of the built environment that creates a sense of belonging and attachment to a place [12]. The physical aspects 
Jaleel, S Cherian, J

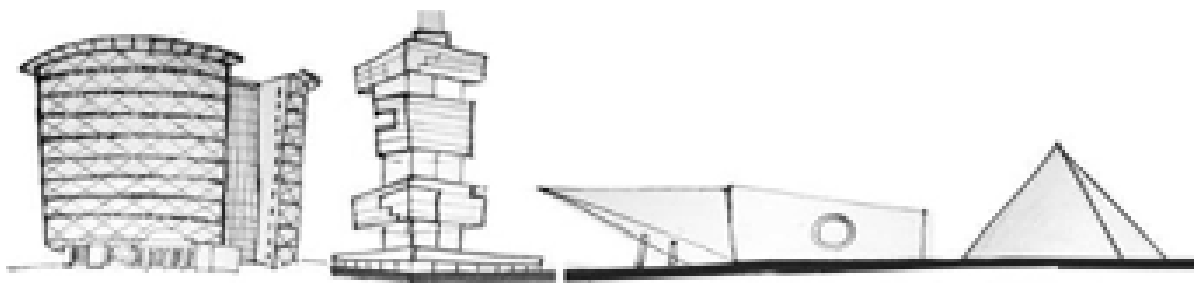

Figure 5: Sketches showing the transplanted competing iconic forms of technocentric developments in Bengaluru (Image source: Authors).

of the urbanscape are urban elements, composition and structuring of physical components of the built environment and, the spatial pattern. Social identity defines groups based on culture, religion, social status, etc. that are further characterised by personal meanings and symbols of different social categories.

People structure their perceptions through abstract social categories that become part of their self-concept and this produces group behaviour [17]. Identity is a dynamic and evolving concept that gets re-negotiated continually based on the changing perceptions and aspirations [20]. It has a structure and process [2]. Identity process has changed from being a means to a goal of dreams. The production of space has changed from spiritual to economic values [4]. People tend to change their physical environment so as to reflect themselves [19]. According to Kevin Lynch, imageability and legibility achieved through urban elements are integral aspects of identity [10]. Genius Loci, which forms the spirit of a place, is contributed through response to topography, natural conditions, symbolism gathered from patterns and inspiration from nature and man-dwelling relationship [11]. Identity parameters have been developed from the theoretical study to analyse the identity of Kazhakuttom (Fig. 6).

\section{RELATED WORKS}

Case studies were conducted on Indian technocentric developments such as the Electronic City and Whitefield in Bengaluru and, the DLF Cyber City in Gurgaon. The latter is a case in which the technocentric work centre has been integrated with the city through introduction of a public realm. Gurgaon is a financial and industrial centre developed along the expressway and surrounded by residential neighbourhoods. The technocentric cluster is well connected through the metro rail system, making it an important city-level public space. The public realm consists of various types of restaurant, seating spaces, LCD screens, amphitheatres for events, and so on -- thus, making it an important node of the city. The development consists of independent firms whose edges are visually permeable, ensuring connections with street. The edge of the 


\begin{tabular}{|c|c}
\hline PLACE & ACTIVITY \\
\hline Strategic location & Clustering \\
\hline Topological organization & Variation, mix \\
\hline Structuring of elements & Inclusiveness \\
\hline $\begin{array}{c}\text { Entry points, Landmarks } \\
\text { Nodes, Edges }\end{array}$ & \multirow{2}{*}{ Events, Festivals } \\
\hline Orientation, axis & \\
\hline Focal centers and paths & \\
\cline { 1 - 1 } Openness & \multirow{2}{*}{ EMOTIONS } \\
\hline Symbols & Perceptions \\
\hline Image, Character, Details & aspirations \\
\hline Scale &
\end{tabular}

Defining The

Identity of

Technocentric

Transformations

In An Urban

Edge - A Case

of Kazhakuttom,

Trivandrum

Figure 6: Tangible and Intangible determinants of Identity of a place derived from the literature study (Image source: Authors).

cyber hub is surrounded by roads, parking lots and linear parks which are inactive due to lack of pedestrian spatial continuity as the development is autooriented. The global aspirations have resulted in a transplanted global image and character lacking identity references that ensure continuity and belonging with the place. Electronic City and Whitefield is an example of a technocentric cluster on the urban edge of Bengaluru (Figs. 7a, 7b, 7c, 7d). Electronic City comprises a concentrated cluster developed on either side of the highway. It has generated new towns and service facilities for the new population, fragmenting the local settlements and creating a dual urban landscape with spatial reflections of socio-economic polarization. Within the clusters, there is growing trend of informal eateries showing the demand for the incorporation of local services. The interface areas within the edge of the technocentric clusters could be developed as areas of opportunity for the same. A common public realm is absent, as the technocentric clusters are mostly embedded in gated developments.

\section{MACRO LEVEL SITE ANALYSIS}

At the macro scale ecological context, the terrain is characterised by coastal lowlands and midlands. Kazhakuttom has an undulating terrain to the right side of the bye-pass and the rail line. The two main water bodies are the 'Kadinamkulam Lake' in the North and the 'Veli-Akkulam Lake' in the south connected by the TS Canal. There is patch of wetlands along the lowest points 
Jaleel, $\mathrm{S}$ Cherian, J

of the ridges with the 'Thettiyar Canal' running through it. The technocentric developments have come up over the wetlands along the bypass road. This filling up of wetlands has caused water logging issues in this area and, may further result in water scarcity in this area (Figs. 8a, 8b).

The major land use is characterised by single-use developments with $37 \%$ residential, $1.3 \%$ commercial, $14.3 \%$ of non-agricultural and public/ semi-public use, followed by $8.5 \%$ of educational landuse. The IT based SEZ occupies $6.2 \%$ of the total. There is a clear lack of recreational and open public uses. IT workers require entertainment facilities, which are lacking (Fig. 9)

The technocentric firms, the major economy and activity generators, have the working population coming from Gurgaon, Chennai, Coimbatore, Bengaluru, Mysore and other parts of Kerala, and require service facilities. Currently these are provided by the local as well as the new population through provision of accommodation facilities, local eateries, dhabas, restaurants, travel agencies, fruit and vegetable stalls, hypermarkets, etc.

Kazhakuttom is currently a second order commercial node of Trivandrum. However, expansion of the new phase and widening of the bypass will trigger technocentric service-based transformations in it. The presence of city-level educational institutions, technocentric clusters also generates high volume of traffic and causes congestion at the major nodes such as the Kazhakuttom Junction and the Manvila Junction.

The major proposals for this region, as specified in the Master Plan include (i) a light metro rail, (ii) a project for developing T.S. Canal National Waterway, linking Akkulam Recreational Hub, (iii) a widening of the bypass to 45m [7] and, (iv) densification of settlements due to its location in the outer city area. Private developments include gated residential developments, Hotels, commerce, etc. (Fig. 10).

\subsection{Micro-level Site Analysis}

The micro-level site is the area adjacent to the Technopark Campus, which will undergo transformation with completion of Phase III. It is limited to the Kazhakuttom commercial node to the Manvila Junction, bound by the railway line and the Karyavattom Campus Road, to the rear of the Technopark. The local settlements along the bypass have started to transform into commercial services. The micro-scale site is a sample of the local settlements and the global technocentric zone undergoing service-based transformations. The residential units are going vertical by additions of lodging facilities and new commercial units are getting added on ground floor along the road fronts. Vacant plots and old residences are being developed into commercial units mainly restaurants and eateries which active in the extended evening hours (Fig. 11). 

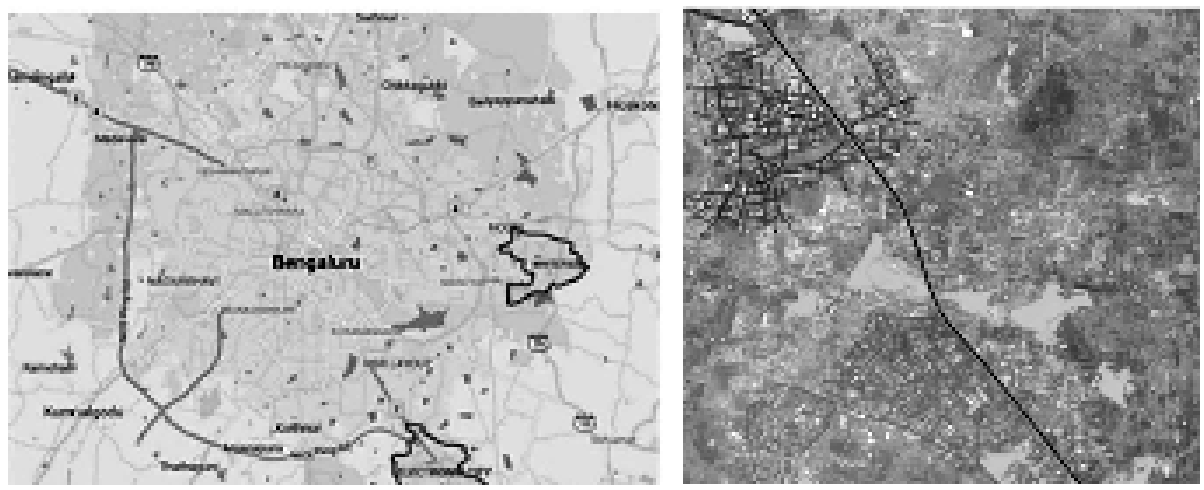

Defining The Identity of Technocentric Transformations In An Urban Edge - A Case of Kazhakuttom, Trivandrum
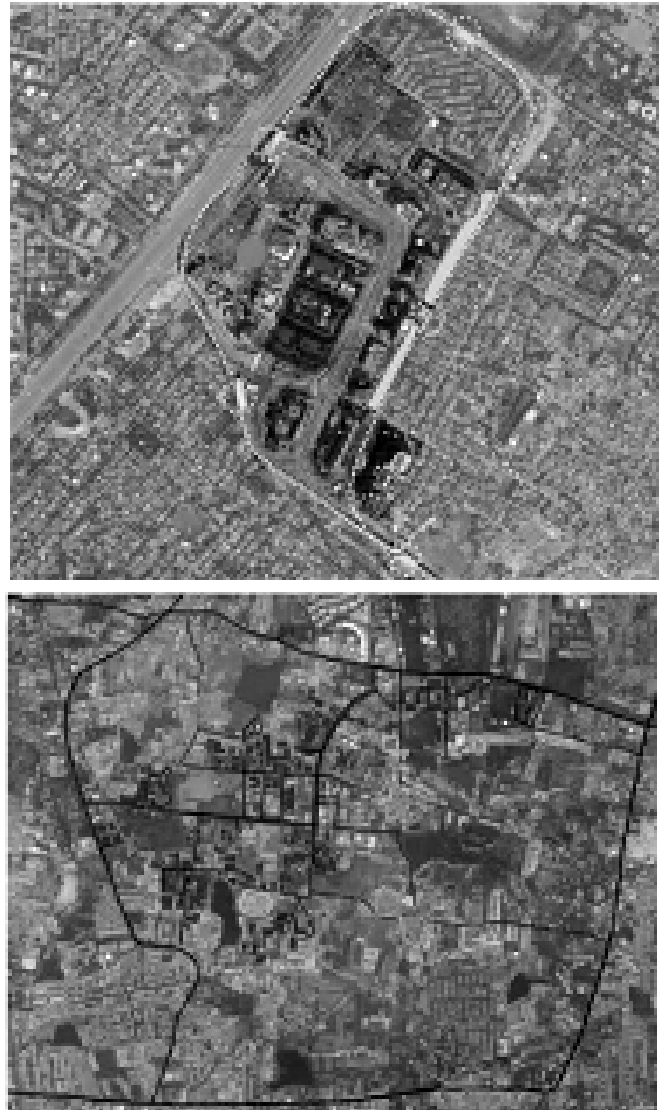

Figure 7a, 7b, 7c, 7d: Image showing the different technocentric contexts in Bengaluru (top left)- Whitefield (bottom left) and Electronic city (top right) and Gurgaon (bottom right) (Image source: Authors adapted data from Google maps).

\subsection{Types of Firms in Technopark}

Technopark Campus has high-level and low-level firms based on the number of employees. There are different types of organisational setups like Tibic, 
Jaleel, S

Cherian, J
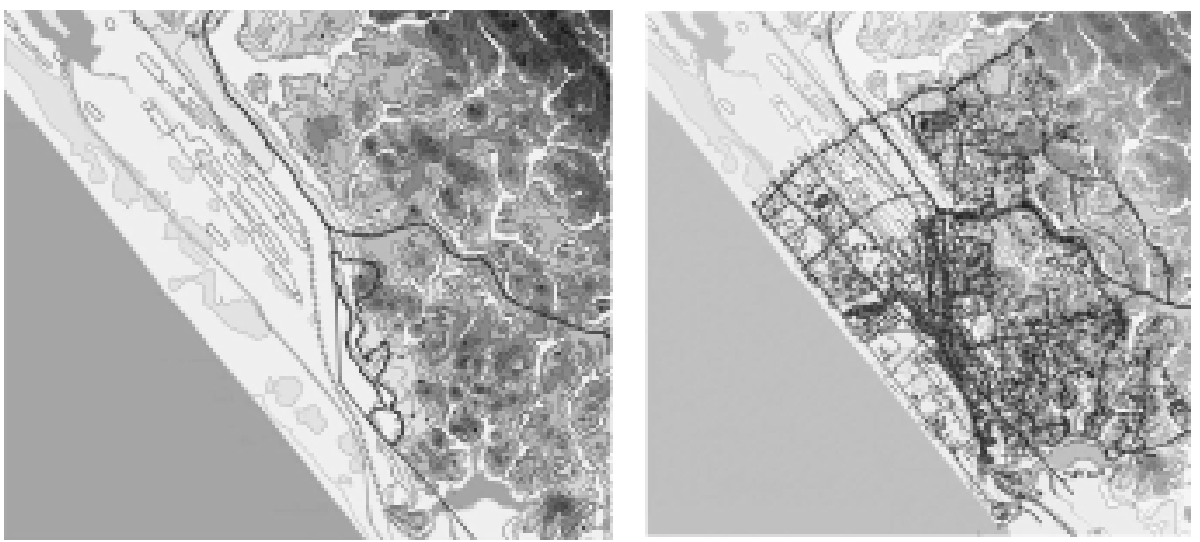

Figure 8a, 8b: Images showing the relief map and the built fabric overlaid on the ecological context of Kazhakuttom (Image source: Authors adapted data available from Center for Earth Science Studies (CESS) and Survey of India Topography map).

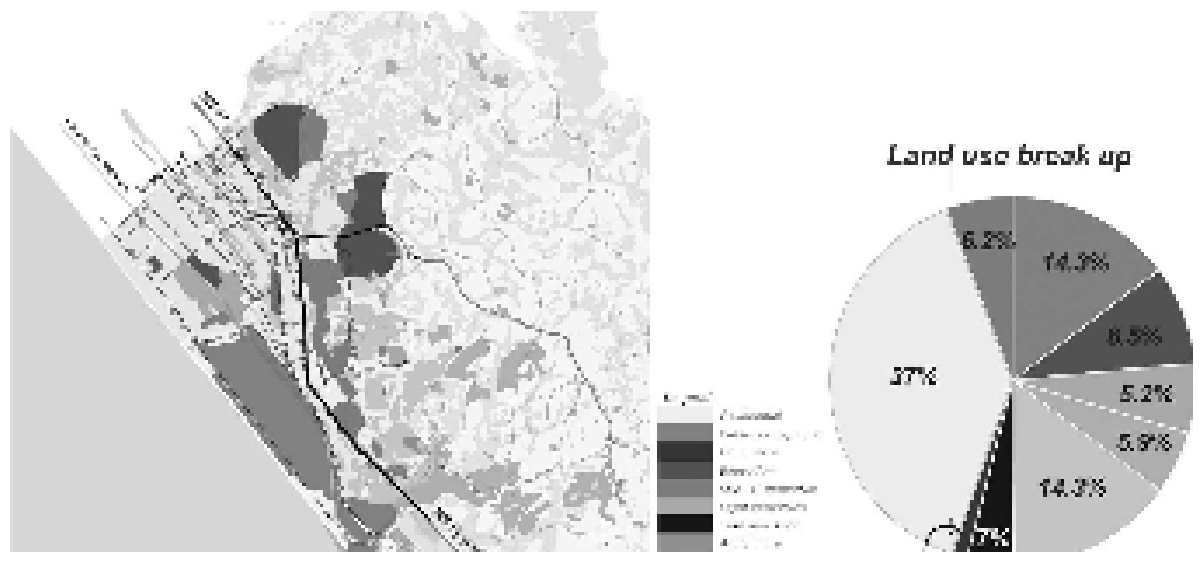

Figure 9: Images showing the land use pattern and land use break up in Kazhakuttom (Image source: Authors adapted data available from Trivandrum draft Master Plan).

SBC (Smart Incubation Centre) for budding companies and, ordinary firms with built space and workstations allotted for companies. Tibic is an incubation centre for Startups with an area less than 50 sq.m and less than 25 employees. SBC is an advanced type of Tibic, with area greater than 50 sq.m and 25-50 employees. The campus provides workstations and related infrastructure for companies, e.g., buildings such as Nila, Gayathri, Pamba, etc. Land is allotted for companies to start units, e.g., Quest, Tata Elixi, etc. 


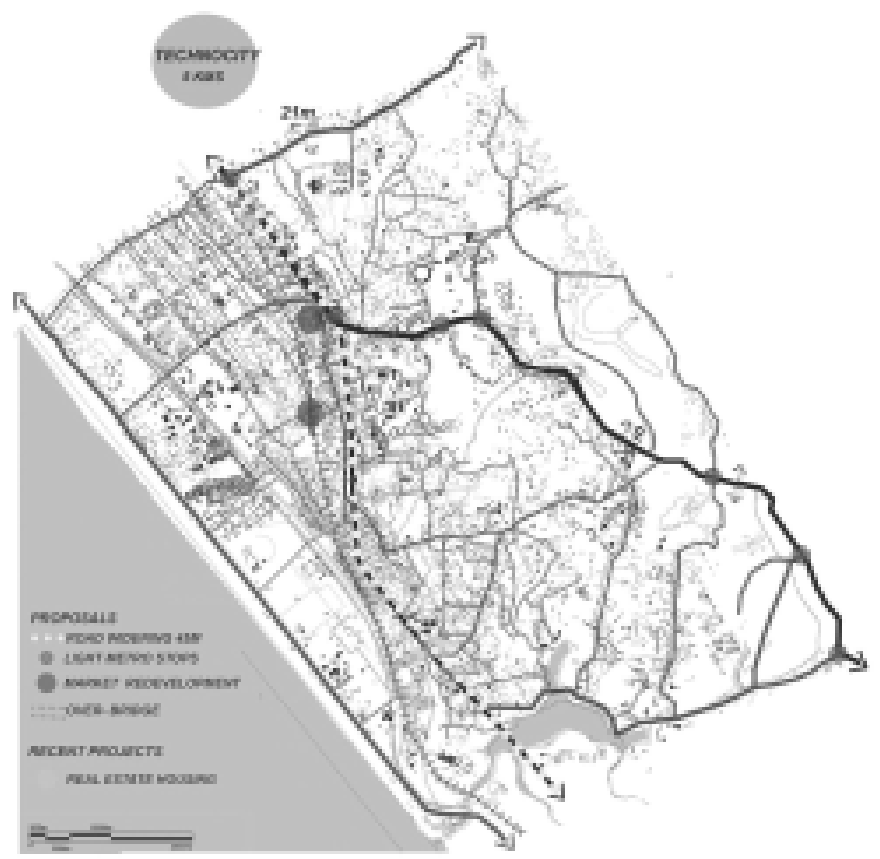

Defining The

Identity of

Technocentric

Transformations

In An Urban

Edge - A Case

of Kazhakuttom,

Trivandrum

Figure 10: Existing Government and private proposals in Kazhakuttom (Image source: Author adapted data available from Thiruvananthapuram Draft Master Plan, November 2012).

\subsection{Work Culture}

The campus functions round the clock in three shifts $-6 \mathrm{am}$ to $2 \mathrm{pm}, 2 \mathrm{pm}$ to $10 \mathrm{pm}$ and, $10 \mathrm{pm}$ to $6 \mathrm{am}$ making it active round-the-clock. The campus has support facilities like food courts, cafeteria, banks, ATMs, pharmacy, and bus bays with bus services from $10 \mathrm{am}$ to $6 \mathrm{pm}$ at half hour intervals. More than $50 \%$ of the workers are from outside Trivandrum and stay in rented accommodations in Kazhakuttom, Manvila and nearby areas. IT professionals use local eateries as the food courts on campus are expensive. In addition, they use the local theatres and beaches for entertainment and recreation.

\subsection{Activity}

Since the Technopark precinct is active round-the-clock, the service facilities in adjoining areas also function for extended hours. The daily activities are shopping, eating, chit-chat and hangouts, cleaning, vending, religious activity near neighbourhoods, recreation, etc. all these provide clues for identifying the possible functions which could be incorporated in the interface of the campus and the local setting. Annual events also include the Technopark Fest for the 
Jaleel, S Cherian, J

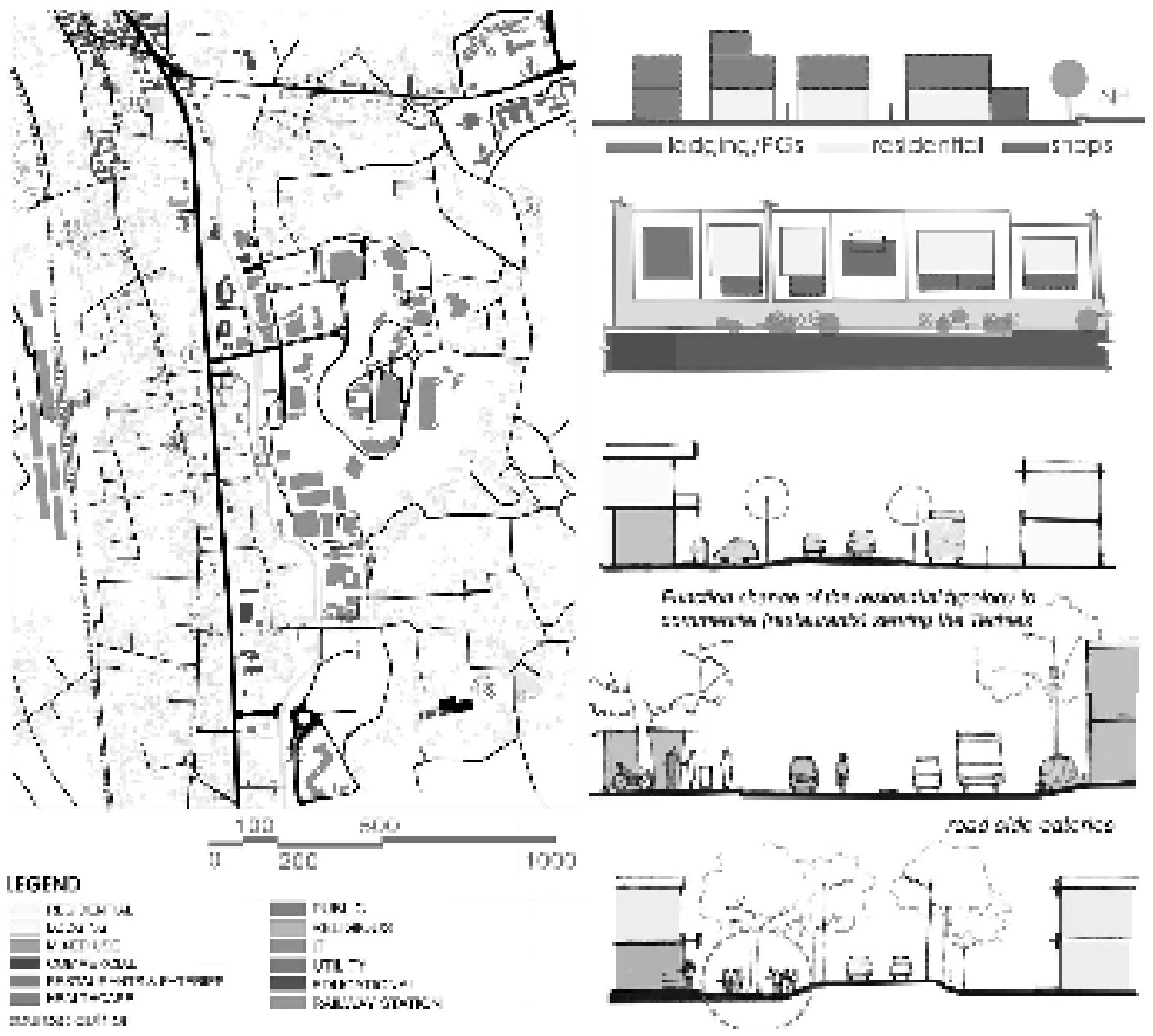

Figure 11: Image showing the built use pattern, residential and commercial transformations in Kazhakuttom (Image source: Authors).

techies conducted in the amphitheater and cricket matches in the campus playfield. Temple festivals are the seasonal events in the local domain.

\section{RESULTS}

The design strategies for an integrated development of the technocentric campus that would ensure a place identity are (Fig. 12):

- Integrating the campus with the context is the major design move. This would be facilitated by identifying potential transformation areas that could be developed as areas of opportunity.

- Provision of mixed-use developments along the interface zone, with higher densities based on the planning proposal for this area. This will limit the sprawling nature of developments and allow for wetland conservation. 

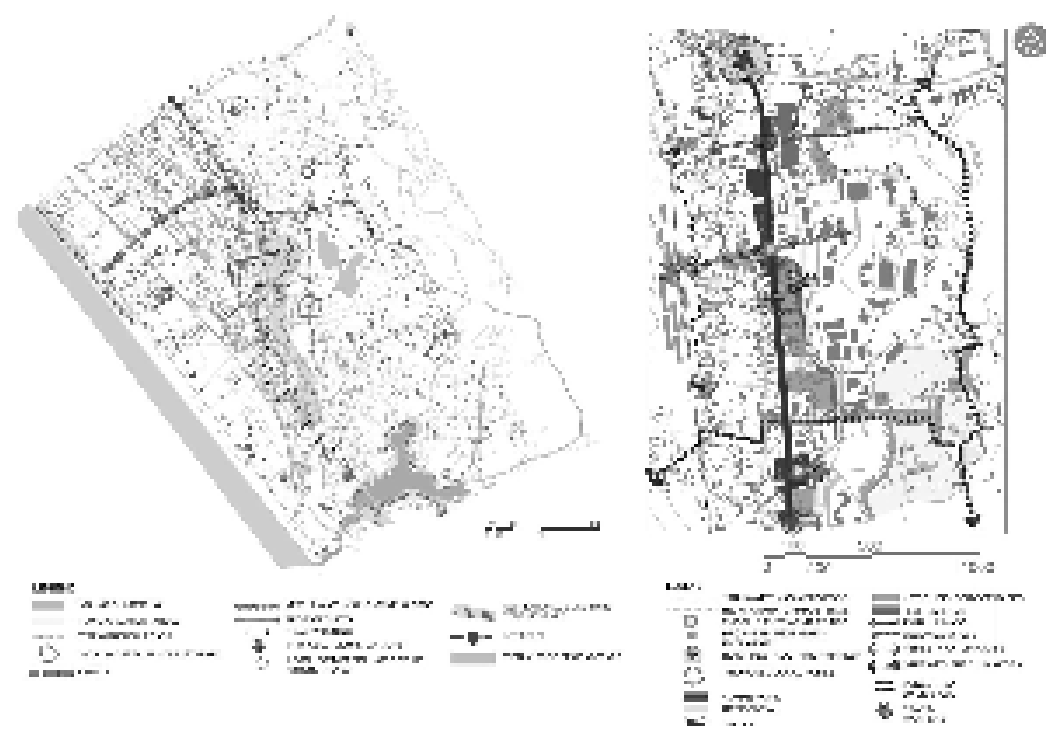

Defining The

Identity of

Technocentric

Transformations

In An Urban

Edge - A Case

of Kazhakuttom,

Trivandrum

Figure 12: Image showing the macro and micro level design strategies (Image source: Authors).

- Incorporation of public recreation and entertainment facilities for both the local and the techie population along stretch of the bypass facing the Technopark along the bypass. This incorporation of a public realm will enhance the identity of Technopark as a major landmark of Kazhakuttom.

- Improving linkages to the surrounding neighbourhoods and the railway station.

- Enhancing the image of the existing local commercial nodes and the potentially imageable elements like the Temple Tank.

- Enhancing place-based identity by incorporating the local and regional spatial patterns and appropriate climatic responses in the new public realm.

\section{DISCUSSIONS AND FUTURE WORKS}

Technocentric developments are increasingly being introduced in cities for economic support. It is essential to ensure an integrated approach, which will contribute to the identity of the place rather than forming an alien reference, and, thus minimize issues of differentiation. The design theories and principles developed in this paper can be used as a preliminary design tool for different technocentric contexts in India. Future works shall focus on policy level 
Jaleel, $\mathrm{S}$ Cherian, $\mathrm{J}$

strategies to ensure local involvement and support in such developments where extroverted, street-facing built forms could be achieved to create active edges.

\section{CONCLUSION}

The design approach involving integration strategies, concepts of identity, glocalization and hybridization will result in a contiguous urban realm in a technocentric context with place based references. The existing transformation along the NH bypass has been made into an opportunity to devise context specific design guidelines to realize Kazhakuttom as the future technocentric hub of the city, aiming at global and local integration with service-based opportunity producing an enhanced place-based identity that will also add value to the imageability of Trivandrum.

\section{REFERENCES}

[1] AHMED A.S.S. (2011) Modernization and regionalism: Approaches for sustainable revival of local urban identity. Procedia Engineering, Vol. 21, pp. 503-512. Available from: http://www.sciencedirect.com/science/ article/pii/S1877705811048788, [Accessed: December 08, 2014].

[2] BREAKWELL, G. M. (1986) Coping with Threatened Identities. London: Metheun..

[3] Census data, Trivandrum District Collectorate, Election data, 2011.

[4] CORREA, C., (1983) Quest for Identity. In: Proceedings of the Seminar on Architecture and Identity, Kuala Lumpur, 198v3. Singapore: Concept Media/Aga Khan Award for Architecture, pp. 10-13.

[5] FRAMPTON. K. (1983) Towards a Critical Regionalism: Six points for an Architecture of Resistance. In: FOSTER, H. (ed.) The Anti-Aesthetic: Essays on Postmodern Culture. 1st ed. Seattle: Bay Press, pp. 16-30.

[6] FRIEDRICH. S. (1998) Spatial Aspects of Cultural Identity and Social Segregation. In: TAN2 Conference Report on Cultural Identity and Spatial Segregation, 5-8 Nov. 1998.

[7] GOVERNMENT OF KERALA. DEPARTMENT OF TOWN AND COUNTRY PLANNING (2012) Thiruvananthapuram Master Plan (Draft). Thiruvanthapuram: Thiruvanthapuram Corporation.

[8] HARVEY, D. (1990) Chapter-17: Time-space compression and the postmodern condition. In: HARVEY, D. The Condition of Postmodernity - An Enquiry into the Origins of Cultural Change. Oxford: Blackwell Publishers, pp. 284-307. 
[9] KUDUG, D.C., CEBI, D.P. (2014) Exploring Emerging Identities and Generation of Hybrid Urban Forms in the City of Doha In: Composite Cities - Proceedings of the European Symposium on Research in Architecture and Urban Design, Istanbul, November 12-14, 2014. Istanbul Technical University, pp. 042:01-15.

[10] LYNCH, K. (1960) The Image of the City. Cambridge, USA: The MIT Press.

[11] NORBERG-SCHULZ, C. (1979) Genius Loci: Towards a Phenomenology of Architecture. New York: Rizzoli.

[12] PROSHANSKY, H.M and FABIAN, A.K. (1987) Chapter-2: The Development of Place Identity in the Child. In: DAVID, T. G. and WEINSTEIN, C. S. (eds.) Spaces for Children - The Built Environment and Child Development. New York: Plenum Press, pp. 21-40.

[13]ROBERTSON. R. (1992) Globalization: Social Ttheory and Global Culture. London: Sage Publications.

[14] SAASEN, S. (1996) Whose city Is It? Globalization and the Formation of New Claims. Public Culture, 8 (2), pp. 205-223. doi:10.1215/089923638-2-205

[15] STALLMEYER,J.C. (2011) Building Bangalore Architecture and Urban Transformation in India's Silicon Valley. New York: Routledge.

[16] SWYNGEDOUW. E. (1997) Neither global nor Local: 'Glocalization' and the Politics of Scale. In: COX, K. (ed.) Spaces of Globalisation: Reasserting the Power of the Local. London: The Guilford Press, pp. 137-166..

[17] TAJFEL. H. (ed.) (1982) Social Identity and Intergroup Relations (European Studies in Social Psychology). Cambridge: Cambridge University Press.

[18] TECHNOPARK (2015) Technopark Phase III. [Online] Technopark: Harmony @ Work. Available from: http://www.technopark.org. [Accessed on: 20/06/2015].

[19] TWIGGER-ROSS, C.L. and UZZEL, D.L. (1996) Place and Identity Process. Journal of Environmental Psychology, 16 (3), pp. 205-220.

[20] TWIGGER-ROSS, C.L., BONAIUTO, M. and BREAKWELL, G. (2003), Identity Theories and Environmental Psychology. In: BONNES, M., LEE, T., and BONAIUTO, M. (eds.) Psychological Theories for Environmental Issues. Aldershot, England: Ashgate Publishing, pp.203-233. 